\title{
Possible association of vitamin D status with lung involvement and outcome in patients with COVID-19: a retrospective study
}

\author{
Alireza Abrishami ${ }^{1} \cdot$ Nooshin Dalili $^{2} \cdot$ Peyman Mohammadi Torbati $^{3} \cdot$ Reyhaneh Asgari $^{4} \cdot$ Mehran Arab-Ahmadi $^{5}$. \\ Behdad Behnam $^{6} \cdot$ Morteza Sanei-Taheri $^{7,8}$
}

Received: 27 May 2020 / Accepted: 6 October 2020 / Published online: 30 October 2020

(c) Springer-Verlag GmbH Germany, part of Springer Nature 2020

\begin{abstract}
Purpose Vitamin D deficiency has been reported as a key factor in the development of infectious diseases such as respiratory tract infections and inflammatory processes like acute respiratory distress syndrome. However, the impact of vitamin D on the severity and outcome of COVID-19 is still not fully known. Herein, we aimed to evaluate the prognostic role of serum vitamin D concentration on the extent of lung involvement and final outcome in patients with COVID-19.

Methods Seventy-three subjects with confirmed diagnosis of COVID-19 were investigated in this study. The patients had been admitted to our academic hospital from February 28, 2020 to April 19, 2020. Demographic and clinical data, serum 25(OH)D levels, and findings of initial chest computed tomography were recorded. Linear and binary logistic regression, cox regression and ROC curve tests were used for statistical analysis.

Results The mean age of patients was $55.18 \pm 14.98$ years old; $46.4 \%$ were male. Mean serum $25(\mathrm{OH}) \mathrm{D}$ concentration was significantly lower in the deceased $(13.83 \pm 12.53 \mathrm{ng} / \mathrm{mL}$ compared with discharged patients $(38.41 \pm 18.51 \mathrm{ng} / \mathrm{mL})$ $(P<0.001)$. Higher levels of $25(\mathrm{OH}) \mathrm{D}$ were associated with significantly less extent of total lung involvement $(\beta=-0.10$, $P=0.004)$. In addition, vitamin D deficiency $[25(\mathrm{OH}) \mathrm{D}<25 \mathrm{ng} / \mathrm{mL}]$ was associated with a significant increase in the risk of mortality (hazard ratio $=4.15, P=0.04$ ).

Conclusion This study suggests that serum vitamin D status might provide useful information regarding the clinical course, extent of lung involvement and outcome of patients with COVID-19. However, further studies with larger sample size are needed to confirm these findings.
\end{abstract}

Keywords COVID-19 · Computed tomography $\cdot$ Vitamin D · Outcome

\section{Introduction}

Coronavirus disease 2019 (COVID-19) is a novel, highly contagious viral infection that has affected many healthcare systems across the world in the recent months. It is caused by the severe acute respiratory syndrome coronavirus 2 (SARSCoV-2) and was initially identified in Wuhan, Hubei, China, in late 2019 [1]. The most common symptoms of COVID19 are cough, fatigue, fever, shortness of breath and sore throat [2]. Nevertheless, the spectrum of disease severity
Alireza Abrishami

abr.alireza@yahoo.com

1 Department of Radiology, Shahid Labbafinejad Hospital, Shahid Beheshti University of Medical Sciences, Tehran, Iran

2 Chronic Kidney Disease Research Center, Shahid Labbafinejad Medical Center, Shahid Beheshti University of Medical Sciences, Tehran, Iran

3 Department of Pathology, Shahid Labbafinejad Medical Center, Shahid Beheshti University of Medical Sciences, Tehran, Iran
4 Department of Radiology, Shohada Tajrish Hospital, Shahid Beheshti University of Medical Sciences, Tehran, Iran

5 Department of Radiology Advanced Diagnostic and Interventional Radiology Research Center, Tehran University of Medical Sciences, Tehran, Iran

6 Department of Internal Medicine, Firoozgar Hospital, Iran University of Medical Sciences, Tehran, Iran

7 Department of Radiology, Shohada Tajrish Hospital, Shahid Beheshti University of Medical Sciences, Tehran, Iran

8 President of Iranian Society of Radiology, Tehran, Iran 
ranges from asymptomatic illness to critical respiratory distress and death [3]. Based on previous reports, elderly patients (older than 60 years) and those with pre-existing comorbidities such as diabetes, hypertension, cardiovascular disease, chronic respiratory disease, and cancer are more likely to suffer from severe disease [4]. Moreover, it is has been shown that different clinical and laboratory factors can also impact COVID-19 disease course and outcome [5, 6]. Hence, it is essential to identify other factors that might possibly make patients prone to more severe form of disease.

Vitamin D is an immunomodulatory hormone that regulates both innate and adaptive immune function [7]. Vitamin D deficiency plays an important role in the development and persistence of inflammation, which is a key feature in the pathogenesis of acute respiratory distress syndrome (ARDS) $[8,9]$. According to previous studies, higher serum concentrations of 25-hydroxyvitamin D (25[OH]D) have been related with reduced risk of influenza progression during winter [10]. 25(OH)D concentration has also been shown to play a possible role in several infectious diseases such as respiratory tract infections (RTI), tuberculosis (TB), human immunodeficiency virus infection (HIV) and sepsis [11]. In addition, vitamin D deficiency is associated with an increased risk of all-cause mortality in the general population [12].

Vitamin D employs different mechanisms in reducing the risk of viral infection and mortality. Several of these mechanisms include maintenance of cell junctions and gap junctions, strengthening of cellular immunity by diminishing the cytokine storm (via modulation of interferon $\gamma$ and tumor necrosis factor- $\alpha$ secretion) and regulating adaptive immunity through inhibiting type $1 \mathrm{~T}$ helper cell responses and stimulating $\mathrm{T}$ cell induction $[10,13]$. Although the antiviral, immunomodulatory and anti-inflammatory effects of Vitamin D have been exhibited in different studies, its effect on COVID-19 has not been studied thoroughly [14].

On the other hand, chest computed tomography (CT) plays an important role in the diagnosis of COVID-19, demonstrating a high sensitivity of approximately $98 \%$ [15]. In addition, chest $\mathrm{CT}$ is considered a useful tool for evaluating the clinical severity of COVID-19 and guiding clinicians for better management of the infection [16].

Bearing this in mind, this study aimed to evaluate the possible existence of an interplay between serum 25(OH)D concentrations and the extent of lung involvement and clinical outcome in patients with COVID-19. We particularly focus on Vitamin D deficient state and the risk of developing poor clinical outcomes in such patients.

\section{Methods}

\section{Patient population}

In this retrospective study, the medical records of 73 confirmed cases of COVID-19 who had been admitted to our academic hospital between February 28, 2020 and April 19, 2020 were reviewed. Diagnosis of COVID-19 was based on the interim guidelines of the World Health Organization (WHO) and also national diagnosis and treatment guidelines of COVID-19. Cases with a time interval of more than three days between the performance of initial chest $\mathrm{CT}$ and measurement of serum $25(\mathrm{OH})$ level were excluded. Also, patients with negative RT-PCR result were not included in our study.

\section{Data collection}

Patients' demographic data and past medical history including the presence of hypertension, diabetes, ischemic heart disease, asthma, chronic lung disease, chronic liver disease, chronic kidney disease [estimated glomerular filtration rate (GFR) based on the Epidemiology Collaboration Equation (CKD- EPI) below $60 \mathrm{cc} / \mathrm{min}$ ] and immunocompromised conditions were recorded. Comorbidity was defined as having any of the aforementioned conditions.

Patients' presenting symptoms including fever, cough, sore throat, dyspnea, chilling, headache, myalgia and gastrointestinal symptoms were collected from medical documents. Also, vital signs (pulse rate, blood pressure, respiratory rate, body temperature, and oxygen saturation on room air) were recorded for each patient. Finally, patients' final disease outcome (death vs discharge) was also collected.

The study protocol was approved by ethics committee of Shahid Beheshti University of Medical Sciences (IR.SBMU. MSP.REC.1399.040). Written consents were obtained from all participants.

\section{Laboratory procedures}

Serum calcium was assessed with photometric analysis by the Hitachi 747 autoanalyzer (Hitachi, Tokyo, Japan) at $37{ }^{\circ} \mathrm{C}$ with Arsenazo III, $200 \mu \mathrm{mol} / \mathrm{L}$ in $50 \mathrm{mmol} / \mathrm{L}$ 1,4-piperazinediethanesulfonic acid (PIPES). Colorimetric analysis was used to assess serum phosphorus with the same device, based on the phosphomolybdic acid, which is then reduced to molybdenum blue. Also, serum magnesium was measured with a colorimetric method based on xylidyl blue reaction. Magnesium ions in alkaline media react with xylidyl blue and produce an estimated $520 \mathrm{~nm}$ wave length. Measurement of 25(OH)D serum concentration was carried out with Roche Diagnostics "Vitamin D Total", cobas e411 
immunoassay analyzer. All laboratory examinations had been performed at admission. Nasopharynx samples were obtained from clinically suspected patients for evaluation by real-time reverse transcriptase polymerase chain reaction (RT-PCR) for SARS-COV-2 [DaAn Gene Co., Ltd. Sun YatSen University, SARS-CoV-2 Virus Detection Diagnostic Kit (RT-PCR Method].

\section{Imaging studies}

All patients had undergone non-contrast lung CT scan utilizing a low dose protocol at admission. All CT scans were obtained with a 64-slice scanner (Siemens sensation; Siemens Healthineers, Erlangen, Germany). The procedures were done in supine position during end-inspiration without contrast medium injection. The scanning parameters were as follows: gantry rotation time of $0.5 \mathrm{~s}, 0.625 \mathrm{~mm} \times 64$-detector array, pitch of 1.4 , table speed of $45.2 \mathrm{~mm} /$ rotation, 20 mAs, $120 \mathrm{kVp}$, and a $300 \times 300$ matrix. CARE Dose4D; CARE $\mathrm{kV}$ scanning parameters were off. One millimeter slice thickness and $1 \mathrm{~mm}$ reconstruction intervals were used for the purpose of reconstruction (sagittal and coronal). Ethanol and didecyldimethyl ammonium chloride were used for the disinfection of imaging facilities and passive air ventilation was also performed in our radiology department.

Chest CT images were interpreted by two expert radiologists with 9 and 18 years of experience, independently. The patterns of involvement were categorized as groundglass opacity (GGO), consolidation, reticular or mixed. The distribution of lung lesions (peripheral, central or both), and the predominant zonal involvement (upper, mid or lower) were also noted. The extent of the lung involvement was assessed using the following scoring system: 0: no involvement, $1:<25 \%, 2: 26-50 \%, 3: 51-75 \%$ and $4:>75 \%$ [16]. The scores for each specific zone of both lungs were summed up to calculate the bilateral zonal score and the total involvement score was calculated by summation of all of the zonal scores (maximum score: 24). Other imaging features including airway thickening, crazy paving, reverse halo sign, dilated vessels, airway dilatation, air-bronchogram, and lymphadenopathy (defined as a lymph node with a short axis $>10 \mathrm{~mm}$ ) and pleural or pericardial effusions were also assessed. Lung zone involvement was classified based on three zones as follows: the upper zone, which was above the carina, the middle zone, defined as the area between the carina and inferior pulmonary vein, and the lower zone, defined as the region below the pulmonary vein [17].

\section{Statistical analysis}

Continuous variables are reported as mean \pm SD for normally distributed data and median (Quartile 1-Quartile 3) for skewed continuous data. Categorical variables are reported as frequency (percentage). Independent sample $T$ test, Mann-Whitney $U$ test, and chi-square test with exact $P$ value were applied to compare continuous and categorical data between deceased and discharged patients. Normality assumption was tested using Shapiro-Wilk test.

Multivariate linear regression analysis was used for evaluating the association between serum $25(\mathrm{OH}) \mathrm{D}$ levels and lung involvement score of the three zones (upper, middle and lower zones) as well as the total lung involvement score. Lung involvement scores were simultaneously entered in the multivariate analysis and were considered as a matrix of dependent variables. The assumptions of errors, variance consistency and normality of residuals were checked in regression models and, if applicable, the appropriate transformation was performed to meet the mentioned criteria. ROC (receiver operating characteristic) curve analysis was conducted to determine the predictive ability of $25(\mathrm{OH}) \mathrm{D}$ in distinguishing final disease outcome (death vs discharge). The optimal cutoff point of $25(\mathrm{OH}) \mathrm{D}$ and its sensitivity and specificity was also calculated.

Binary logistic regression model was applied to determine the relationship between $25(\mathrm{OH}) \mathrm{D}$ deficiency and final outcome (death vs discharged); odds ratio (OR) and 95\% confidence interval were also reported to show the intensity and direction of the relationship. Finally, considering "death" as event and length of hospitalization as "event time", survival and proportional hazards cox regression analyses were performed to evaluate the effect of $25(\mathrm{OH}) \mathrm{D}$ deficiency on the hazard rate (HR) of death in patients with COVID-19. The assumption of proportionality of hazards in cox survival models was checked by Schoenfeld residues and $\log$ minus $\log$ functions, which are reported in Fig. 1. All statistical analysis was performed by STATA 14 and SPSS 24 software. $P<0.05$ was considered statistically significant.

\section{Results}

\section{Patients' demographic and clinical characteristics and imaging findings}

Overall, 73 patients with confirmed COVID-19 were included in this study. The mean \pm SD age of patients was $55.18 \pm 14.98$ years old; 29 (39.7\%) were older than 60 years. Approximately $64 \%$ of patients were male. Fortytwo patients $(57.5 \%)$ reported at least one underlying comorbidity. The median duration of hospitalization was 10 days (range: $1-36)$ and 12 patients (16.4\%) had eventually experienced COVID-19 related death.

Table 1 shows the baseline characteristics of patients in the discharged and deceased groups. Among investigated variables, age, gender, lung involvement pattern and lesion distribution did not differ significantly between the two study 


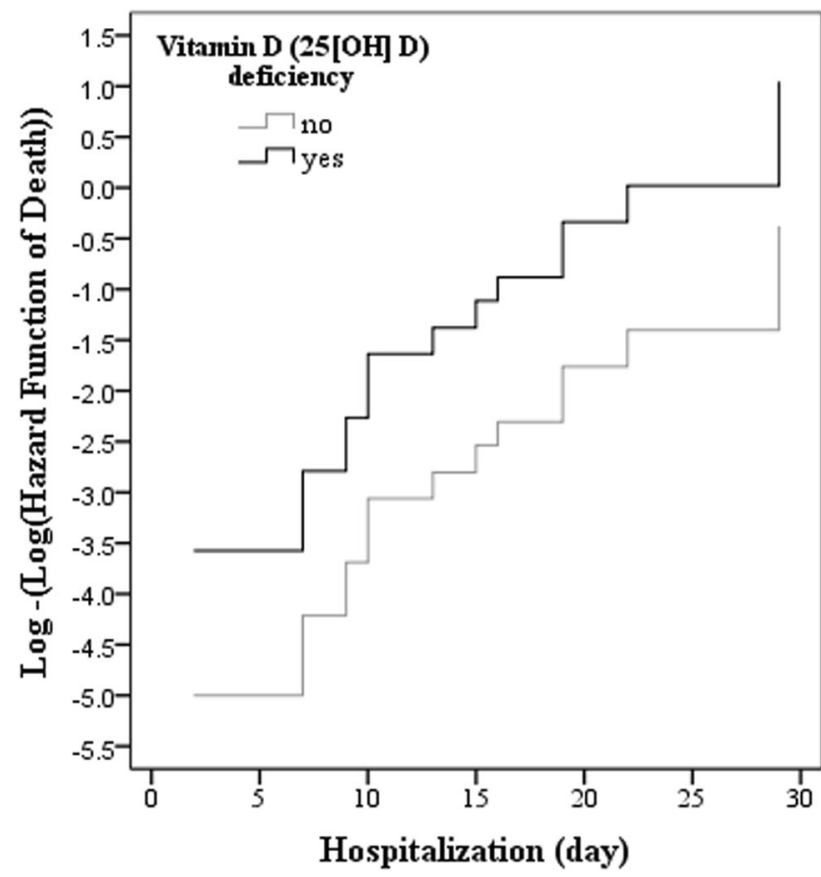

Fig. 1 Log minus log of hazard function. The evaluation of the assumption of proportionality of hazards in cox survival models. The parallel log minus log functions in $25(\mathrm{OH}) \mathrm{D}$ deficiency groups and Schoenfeld residues analysis (chi-square $=8.02, \mathrm{DF}=4, P=0.10$ ) indicates that comparing hazard of death in two groups does not depend on time and the proportionality assumption is hold in cox regression

groups $(P>0.05)$. Zonal lung involvement scores (upper, middle and lower zone) as well as the total lung involvement score were significantly higher in the deceased group $(P<0.01)$.

None of the presenting signs and symptoms differed significantly between the two groups $(P>0.05)$. Among CT imaging findings, dilated vessel $(60.7 \%$ vs $100 \%, P=0.006)$ and air bronchogram $(23.0 \%$ vs $58.3 \%, P=0.007)$ were more likely to be seen in the deceased compared with the discharged patients. Also, the mean concentration of serum $25(\mathrm{OH}) \mathrm{D}$ was significantly lower in patients who died $(13.83 \pm 12.53 \mathrm{ng} / \mathrm{mL})$ in comparison with the survivors $(38.41 \pm 18.51 \mathrm{ng} / \mathrm{mL})(P<0.001)$.

\section{Association between serum vitamin D level and lung involvement scores}

The association between $25(\mathrm{OH}) \mathrm{D}$ concentration and lung involvement scores is shown in Table 2. As demonstrated by the results of multivariate linear regression analysis, a higher $25(\mathrm{OH}) \mathrm{D}$ concentration was significantly associated with less extent of lung involvement $(\mathrm{P}<0.01)$. Also, according to adjusted multivariate regression analysis, higher $25(\mathrm{OH}) \mathrm{D}$ levels were significantly associated with a lower amount of upper $(\beta=-0.03, P=0.003)$, middle $(\beta=-0.03$, $P=0.005)$, lower $(\beta=-0.04, P=0.01)$ and total $(\beta=-0.10$, $P=0.004)$ lung involvement.

By defining severe lung involvement as total lung involvement score $>12$, the relationship between $25(\mathrm{OH}) \mathrm{D}$ concentration and extent of lung involvement was assessed using logistic regression. The results of this analysis showed that one unit increase in the $25(\mathrm{OH}) \mathrm{D}$ level leads to four percent reduction in the odds of developing severe lung involvement $(\mathrm{OR}=0.96,95 \%$ CI $0.93-0.98, P=0.04)$. The effect of potential confounders including sex, age and comorbidity status was adjusted in this evaluation. Figure 2 shows the extent of lung involvement in the CT images of two patients with different levels of $25(\mathrm{OH}) \mathrm{D}$.

\section{Optimal cut-off value of vitamin D for predicting final outcome (death vs discharge)}

The ROC curve analysis for serum Vitamin D is shown in Fig. 3. The area under the curve (AUC) for distinguishing survivors from non-survivors was $0.82(P=0.001)$ and the optimal cut-off level was $<25 \mathrm{ng} / \mathrm{mL}$, with $75 \%$ specificity and $72 \%$ sensitivity (Table 3 ).

\section{The effect of vitamin D deficiency on the risk of mortality}

The probability of death in patients with vitamin $\mathrm{D}$ deficiency [defined as $25(\mathrm{OH}) \mathrm{D}$ concentration $<25 \mathrm{ng} / \mathrm{mL}$ ] was $34.6 \%$ compared with $6.4 \%$ in patients with sufficient vitamin D levels $(P=0.003)$. Logistic regression analysis revealed that the odds of death was significantly higher in vitamin $\mathrm{D}$ deficient patients $(<25 \mathrm{ng} / \mathrm{mL})$ in comparison with discharged patients in both unadjusted $(\mathrm{OR}=7.77$, $P=0.005)$ and adjusted models $(\mathrm{OR}=6.84, P=0.01)$. Also, by considering death as the "event" and length of hospitalization as "event time", cox regression analysis was performed to evaluate the effect of Vitamin D deficiency on the hazard rate of death in COVID-19 patients. In adjusted as well as unadjusted cox models, vitamin $\mathrm{D}$ deficient status increased the hazard of death $(\mathrm{HR}=4.15, P=0.04)$ (Table 4). Figure 4 indicates the higher risk of death in vitamin D deficient patients during hospitalization.

\section{Discussion}

To the best of our knowledge, this is the first study to assess the possible association between clinical features, extent of lung involvement and outcome of COVID-19 with patients' serum 25(OH)D concentration. The results of the present study showed that lower concentrations of serum $25(\mathrm{OH})$ $\mathrm{D}$ are significantly associated with greater extent of lung 
Table 1 Comparing patient's baseline characteristics, comorbidity factors, laboratory, and lung CT scan findings based on outcomes

\begin{tabular}{|c|c|c|c|c|}
\hline Variables & $\begin{array}{l}\text { Total } \\
N=73\end{array}$ & $\begin{array}{l}\text { Discharged } \\
N=61(83.6 \%)\end{array}$ & $\begin{array}{l}\text { Death } \\
N=12(16.4 \%)\end{array}$ & $P$ \\
\hline Age & $55.18 \pm 14.98$ & $54.92 \pm 15.31$ & $56.50 \pm 13.71$ & 0.74 \\
\hline Sex & & & & 0.12 \\
\hline Male & 47 (64.4) & $37(60.7)$ & $10(83.3)$ & \\
\hline Female & $26(35.6)$ & $24(39.3)$ & $2(16.7)$ & \\
\hline \multicolumn{5}{|l|}{ Signs and symptoms } \\
\hline Fever & $43(58.9)$ & $36(59.0)$ & $7(58.3)$ & 0.97 \\
\hline Cough & $50(68.5)$ & $43(70.5)$ & $7(58.3)$ & 0.50 \\
\hline Sore throat & $7(9.6)$ & $7(11.5)$ & $0(0)$ & 0.59 \\
\hline Dyspnea & $47(64.4)$ & $40(65.6)$ & $7(58.3)$ & 0.74 \\
\hline Chilling & $13(17.8)$ & $12(19.7)$ & $1(8.3)$ & 0.68 \\
\hline Headache & $7(9.6)$ & $7(11.5)$ & $0(0)$ & 0.59 \\
\hline Myalgia & $18(24.7)$ & $16(26.2)$ & $2(16.7)$ & 0.72 \\
\hline Nausea & $7(9.6)$ & $6(9.8)$ & $1(8.3)$ & 0.99 \\
\hline Abdominal pain & $7(9.6)$ & $6(9.8)$ & $1(8.3)$ & 0.99 \\
\hline Diarrhea & $6(8.2)$ & $5(8.2)$ & $1(8.3)$ & 0.61 \\
\hline \multicolumn{5}{|l|}{ Comorbidity factors } \\
\hline Asthma/COPD & $7(9.6)$ & $6(9.8)$ & $1(8.3)$ & 0.99 \\
\hline Diabetes mellitus & $11(15.1)$ & $10(16.4)$ & $1(8.3)$ & 0.68 \\
\hline Ischemic heart disease & $13(17.8)$ & $10(16.4)$ & $3(25.0)$ & 0.44 \\
\hline Hypertension & $18(24.7)$ & $17(27.9)$ & $1(8.3)$ & 0.27 \\
\hline Chronic kidney disease & $16(21.9)$ & $9(14.8)$ & $7(58.3)$ & 0.003 \\
\hline Liver disease & $1(1.4)$ & $1(1.6)$ & $0(0)$ & 0.99 \\
\hline Immune system disorders & $10(13.7)$ & $5(8.2)$ & $5(41.7)$ & 0.008 \\
\hline Comorbidity* & $42(57.5)$ & $33(54.1)$ & $9(75.0)$ & 0.18 \\
\hline Oxygen saturation & $90(86.5-93)$ & $90(86.5-93)$ & $88(85.5-90)$ & 0.11 \\
\hline Hospitalization (day) & $10(7-17)$ & $10(7-16)$ & $14(9.3-19)$ & 0.22 \\
\hline \multicolumn{5}{|l|}{ Laboratory findings } \\
\hline $25(\mathrm{OH}) \mathrm{D}$ & $35.19 \pm 19.05$ & $38.41 \pm 18.51$ & $13.83 \pm 12.53$ & $<0.001$ \\
\hline $\mathrm{Ca}$ & $8.94 \pm 0.68$ & $8.50 \pm 0.72$ & $8.71 \pm 0.62$ & 0.95 \\
\hline $\mathrm{P}$ & $3.65 \pm 0.62$ & $3.58 \pm 0.58$ & $3.93 \pm 0.81$ & 0.33 \\
\hline $\mathrm{Mg}$ & $2.07 \pm 0.66$ & $2.11 \pm 0.70$ & $1.84 \pm 0.18$ & 0.40 \\
\hline CT scan involvement pattern & & & & 0.26 \\
\hline Ground glass opacities & $47(64.4)$ & $40(65.6)$ & $7(58.3)$ & \\
\hline Consolidation & $13(17.8)$ & $9(14.8)$ & $4(33.3)$ & \\
\hline Reticular & $8(11.0)$ & $8(13.1)$ & $0(0)$ & \\
\hline Mixed & $5(6.8)$ & $4(6.6)$ & $1(8.3)$ & \\
\hline Involvement distribution & & & & 0.95 \\
\hline Peripheral & $53(72.6)$ & $44(72.1)$ & $9(75.0)$ & \\
\hline Central & $8(11.0)$ & $7(11.5)$ & $1(8.3)$ & \\
\hline Both & $12(16.4)$ & $10(16.4)$ & $2(16.7)$ & \\
\hline \multicolumn{5}{|l|}{ Zone involvement score } \\
\hline Upper & $2(1-3)$ & $2(0-3)$ & $3.5(2.2-5)$ & 0.005 \\
\hline Middle & $3(2-6)$ & $3(2-4)$ & $6(5-6.8)$ & $<0.001$ \\
\hline Lower & $4(2-6)$ & $3(2-5)$ & $7(4.3-8)$ & $<0.001$ \\
\hline Total lung & $8(5-15)$ & $8(5-11)$ & $16(13.5-18.8)$ & $<0.001$ \\
\hline \multicolumn{5}{|l|}{ CT-scan findings } \\
\hline Airway thickening & $57(78.1)$ & $46(75.4)$ & $11(91.7)$ & 0.28 \\
\hline Crazy paving & $7(9.6)$ & $6(9.8)$ & $1(8.3)$ & 0.99 \\
\hline Reverse halo & $1(1.4)$ & $1(1.6)$ & $0(0)$ & 0.99 \\
\hline Lymph node & $4(5.5)$ & $3(4.9)$ & $1(8.3)$ & 0.52 \\
\hline
\end{tabular}


Table 1 (continued)

\begin{tabular}{lllll}
\hline Variables & $\begin{array}{l}\text { Total } \\
N=73\end{array}$ & $\begin{array}{l}\text { Discharged } \\
N=61(83.6 \%)\end{array}$ & $\begin{array}{l}\text { Death } \\
N=12(16.4 \%)\end{array}$ & $P$ \\
\hline Dilated vessel & $49(67.1)$ & $37(60.7)$ & $12(100)$ & 0.006 \\
Airway dilatation & $34(46.4)$ & $25(41.0)$ & $9(75.0)$ & 0.05 \\
Air bronchogram & $21(28.8)$ & $14(23.0)$ & $7(58.3)$ & 0.03 \\
Septal thickening & $10(13.7)$ & $8(13.1)$ & $2(16.7)$ & 0.67 \\
\hline
\end{tabular}

Data are represented as mean $\pm \mathrm{SD}$, median $(\mathrm{Q} 1-\mathrm{Q} 3)$, and frequency (percent)

Mean and median differences were tested using independent $T$ test and Mann-Whitney $U$ test, respectively. The distributions of categorical data were compared by chi-square test (with exact $P$ value)

*At least one of the comorbidity features is positive

Table 2 Multivariate linear regression results in the association of $25(\mathrm{OH}) \mathrm{D}$ concentration and lung involvement scores

\begin{tabular}{|c|c|c|c|c|c|c|c|c|}
\hline \multirow[t]{2}{*}{ Variables } & \multicolumn{2}{|l|}{ Upper Zone } & \multicolumn{2}{|l|}{ Middle zone } & \multicolumn{2}{|l|}{ Lower zone } & \multicolumn{2}{|l|}{ Total } \\
\hline & $\beta(\mathrm{SE})$ & $P$ & $\beta(\mathrm{SE})$ & $P$ & $\beta(\mathrm{SE})$ & $P$ & $\beta(\mathrm{SE})$ & $P$ \\
\hline $25(\mathrm{OH}) \mathrm{D}^{*}$ & $-0.04(0.011)$ & 0.003 & $-0.04(0.012)$ & 0.003 & $-0.03(0.014)$ & 0.02 & $-0.11(0.034)$ & 0.003 \\
\hline Age & $0.02(0.014)$ & 0.29 & $0.03(0.015)$ & 0.038 & $0.04(0.018)$ & 0.04 & $0.08(0.042)$ & 0.05 \\
\hline Sex (male) & $0.79(0.44)$ & 0.08 & $0.67(0.47)$ & 0.16 & $-0.55(0.56)$ & 0.33 & $0.91(1.34)$ & 0.50 \\
\hline Comorbidity (yes) & $0.78(0.42)$ & 0.07 & $1.09(0.45)$ & 0.018 & $0.68(0.54)$ & 0.21 & $2.55(1.28)$ & 0.05 \\
\hline $25(\mathrm{OH}) \mathrm{D} * *$ & $-0.03(0.011)$ & 0.003 & $-0.03(0.012)$ & 0.005 & $-0.04(0.014)$ & 0.01 & $-0.10(0.034)$ & 0.004 \\
\hline
\end{tabular}

*Unadjusted multivariate model

**Adjusted multivariate model

involvement and poorer outcome in patients with COVID19. Moreover, based on both unadjusted and adjusted models of logistic regression analysis, the odds of death were significantly higher in vitamin $\mathrm{D}$ deficient patients $(25(\mathrm{OH})$ $\mathrm{D}<25 \mathrm{ng} / \mathrm{mL}$ ).

In a meta-analysis by Martineau et al., it was shown that vitamin D supplementation significantly decreases the chance of experiencing at least one acute respiratory tract infection. In particular, vitamin D supplementation showed a stronger protective effect in patients with a serum $25(\mathrm{OH})$ D level of less than $10 \mathrm{ng} / \mathrm{mL}$ [18].

A recent study, conducted across 20 European countries, aimed to investigate the association of serum vitamin $\mathrm{D}$ level with COVID-19-related morbidity and mortality. The results of this study showed that the mean level of serum vitamin $\mathrm{D}$ in each country has a significant relationship with the number of infected cases as well as the mortality rate of that specific country $[19,20]$. Patients who are more likely to be vitamin $\mathrm{D}$ deficient such as the elderly and people of the black and minority ethnic (BAME) heritage have been shown to be prone to severe COVID-19. Nevertheless, infants and children experience milder forms of the disease despite the fact that they are at an increased risk of vitamin $\mathrm{D}$ deficiency compared with adults [10]. In this study, we aimed to report serum $25(\mathrm{OH}) \mathrm{D}$ levels in all inpatients and outpatients with COVID-19 and during different stages of the disease. Although some trials are in progress, thus far, no study has investigated the effect of vitamin D on the course and outcome of COVID-19, Hence, a practical guideline advising the use of vitamin D supplements in the general population or in critically ill patients with COVID-19 has not been introduced yet. Based on a previous study that was conducted on patients with respiratory disease, Ebadi et al. suggested a treatment plan for vitamin D supplementation, which could quickly and safely increase serum $25(\mathrm{OH}) \mathrm{D}$ levels [21]. They suggested that patients with low circulating levels of vitamin D (below $50 \mathrm{nmol} / \mathrm{L}$ ) should be offered $50,000 \mathrm{IU}$ of vitamin D supplementation twice weekly at diagnosis. Then, following the initial dose (100,000 IU), patients should continue with a dosage of 50,000 IU once a week for the second and third week of treatment. Patients at higher risk of developing COVID-19 infection such as those with diabetes, transplant recipients [22] or the elderly could consider taking a daily oral dose of $1000 \mathrm{IU}$ for a few weeks to raise their serum level of vitamin D above 30-50 ng/ml. Indeed for therapeutic intention, larger doses are probably required.

Recently, a growing body of literature has focused on the advantages of calcifediol compared with cholecalciferol for vitamin D supplementation. Unlike calcifediol, cholecalciferol guarantees an exact dosage of vitamin D and has pharmacokinetic properties that allow for daily or even weekly 

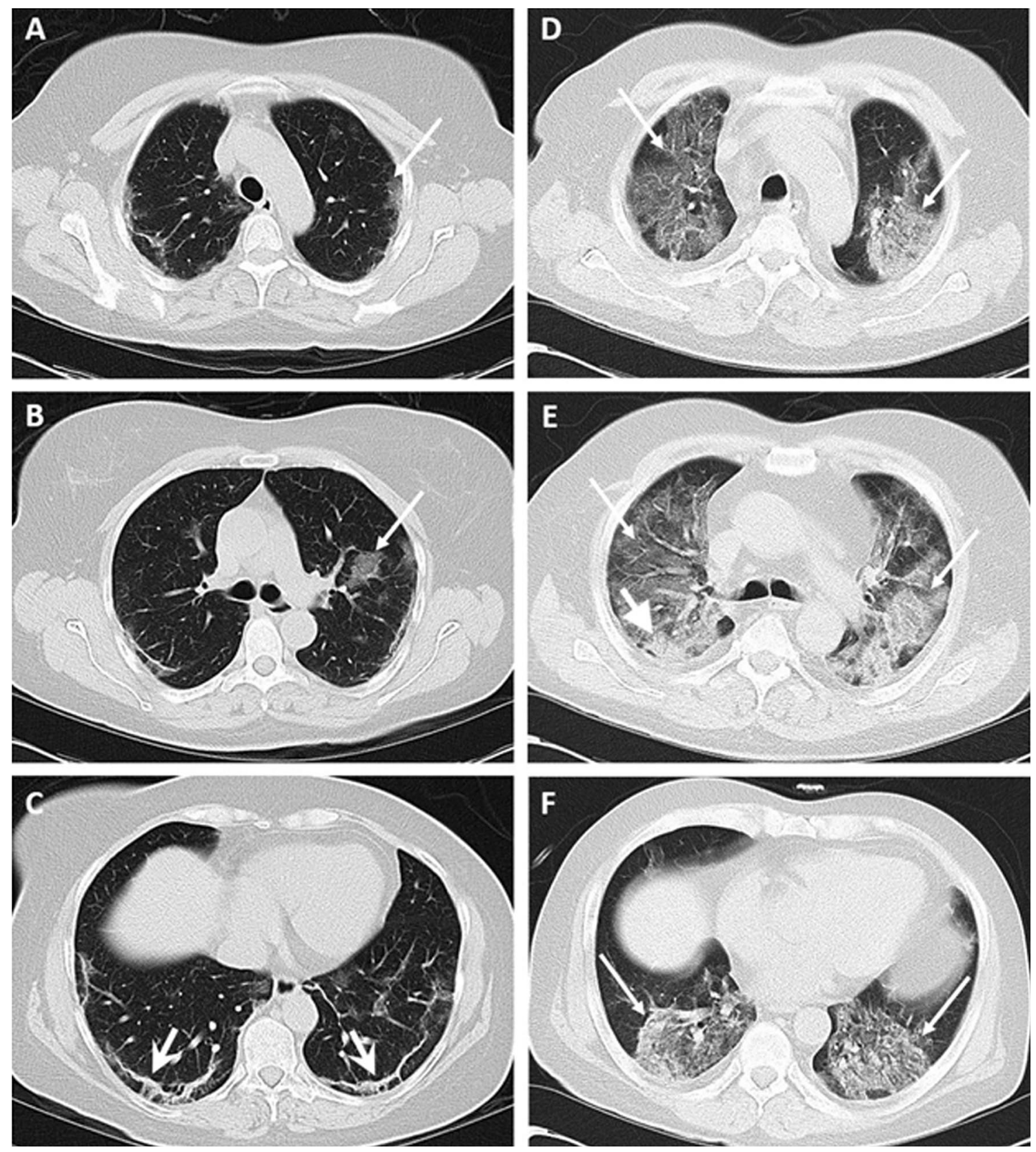

Fig. 2 a-c A 55-year-old man presented with 5-day history of fever and dry cough without any comorbidity [25(OH)D level was $40 \mathrm{ng} /$ $\mathrm{mL}$ ] with initial lung computed tomography (CT) involvement score of eight/24. On admission, CT images showed subtle patchy groundglass opacities (GGO) (long arrows) predominantly in upper zones and reticular pattern (wide arrows) in lower zones. The patient dis-

or monthly administration of vitamin D in equivalent doses, facilitating adherence to treatment. Furthermore, regardless of the pattern of administration, cholecalciferol is more likely to achieve serum levels of $30-50 \mathrm{ng} / \mathrm{mL}$ of $25(\mathrm{OH}) \mathrm{D}$

charged after 6 days. d-f A 54-year-old man presented with 4-day history of fever, dry cough and dyspnea and no other comorbidity [25(OH)D level was $7 \mathrm{ng} / \mathrm{mL}$ ]. Lung CT score involvement score of ninety/24. On admission, CT images showed diffuse GGO (long arrows) with slight consolidation change (thick head arrow) in right mid zone. The patient died after 19 days

[23]. On the other hand, compared to oral cholecalciferol, oral calcifediol results in a more rapid increase in serum $25(\mathrm{OH}) \mathrm{D}$, is more potent and has a higher rate of intestinal absorption. In addition, it has a linear dose-response 


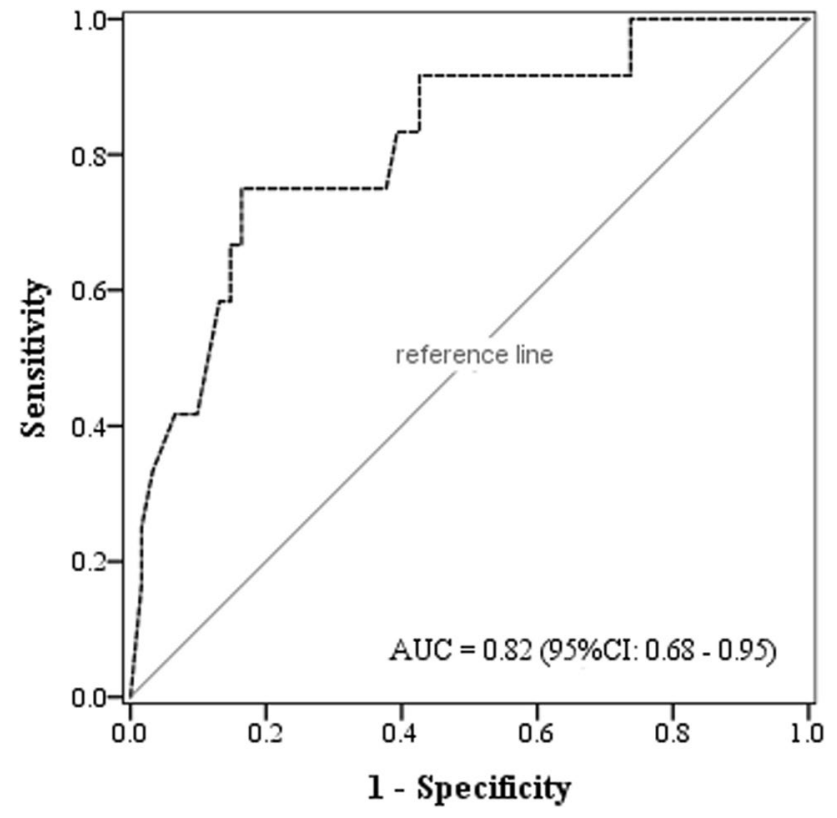

Fig. 3 ROC curve analysis results to achieve predictive values of $25(\mathrm{OH}) \mathrm{D}$ in classifying patients into dead or discharge curve that can result in fairly stable levels of serum $25(\mathrm{OH})$ $\mathrm{D}$, irrespective of baseline $25(\mathrm{OH}) \mathrm{D}$ concentration [24]. It seems that administering oral cholecalciferol should be preferred in the general population with COVID-19 while in ICU patients and in patients with intestinal malabsorption syndromes, calcifediol is a more appropriate alternative.

Zhao and colleagues proposed that chest CT could be a useful tool in assessing the severity of COVID-19 infection [25]. Our study showed that higher levels of $25(\mathrm{OH}) \mathrm{D}$ are associated with decreased amount of lung involvement on chest CT, possibly suggesting a milder form of disease.

Our study had some limitations such as the single center design and small sample size.

In conclusion, this study provides new evidence for clinicians and health policy makers to consider vitamin D supplementation for the improvement of clinical outcome of patients with COVID-19. We believe that vitamin D might be able to protect patients against developing severe form of disease once infected.

Table 3 ROC curve analysis results in differentiating dead and discharged patients using $25(\mathrm{OH}) \mathrm{D}$ levels

\begin{tabular}{llllllll}
\hline Variable & AUC $(95 \% \mathrm{CI})$ & $P$ & Cutoff & Sensitivity & Specificity & PLR & NLR \\
\hline 25(OH) D & $0.82(0.68-0.95)$ & 0.001 & $<25$ & 0.75 & 0.72 & 2.68 & 0.34 \\
\hline
\end{tabular}

$P L R$ positive likelihood ratio, $N L R$ negative likelihood ratio

Table 4 The hazard and odds of death affected by $25(\mathrm{OH})$ $\mathrm{D}$ deficiencies in patients with COVID-19

\begin{tabular}{|c|c|c|c|c|c|}
\hline \multirow[t]{2}{*}{ Models } & \multirow[t]{2}{*}{ Variables } & \multicolumn{2}{|l|}{ Logistic model } & \multicolumn{2}{|l|}{ Cox model } \\
\hline & & OR $(95 \%$ CI $)$ & $P$ & HR (95\% CI) & $P$ \\
\hline Model 1 & 25(OH) D deficiency & $7.77(1.87-32.17)$ & 0.005 & $3.91(1.05-14.54)$ & 0.04 \\
\hline \multirow[t]{4}{*}{ Model 2} & Age & $1.01(0.96-1.06)$ & 0.65 & $1.01(0.97-1.06)$ & 0.69 \\
\hline & Sex (male) & $2.38(0.43-13.12)$ & 0.32 & $1.31(0.24-7.09)$ & 0.75 \\
\hline & Comorbidity (yes) & $2.54(0.57-11.34)$ & 0.22 & $0.98(0.22-3.51)$ & 0.86 \\
\hline & $25(\mathrm{OH}) \mathrm{D}$ deficiency & $6.84(1.55-30.19)$ & 0.01 & $4.15(1.07-16.19)$ & 0.04 \\
\hline
\end{tabular}

Model 1: crude effect, Model 2: adjusted effect

OR Odds Ratio, HR Hazard Ratio, CI Confidence interval 


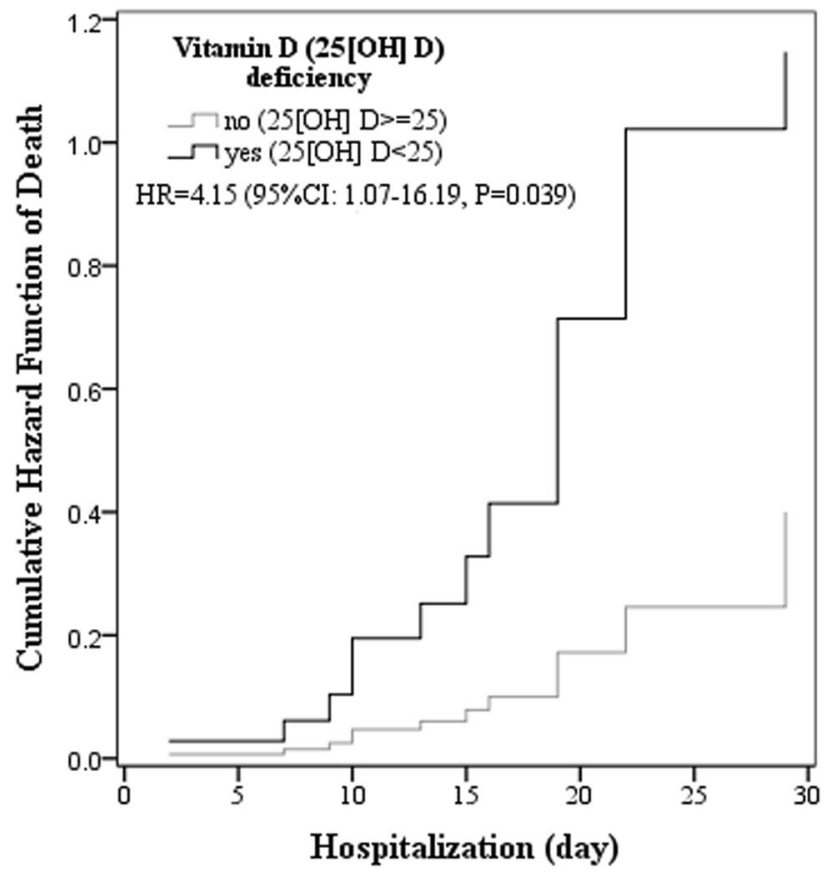

Fig. 4 Cumulative hazard function of death in patients with and without $25(\mathrm{OH}) \mathrm{D}$ deficiency. The "death" status considered as the event and hospitalization days considered as the event time in cox regression

Funding None.

\section{Compliance with ethical standards}

Conflict of interest All authors declare that they have no conflict of interest.

\section{References}

1. Zhu N, Zhang D, Wang W, Li X, Yang B, Song J, Zhao X, Huang B, Shi W, Lu R (2020) A novel coronavirus from patients with pneumonia in China, 2019. N Engl J Med 382:727-733

2. Guan W-j, Ni Z-y, Hu Y, Liang W-h, Ou C-q, He J-x, Liu L, Shan H, Lei C-1, Hui DS (2020) Clinical characteristics of coronavirus disease 2019 in China. N Engl J Med 382:1708-1720

3. Report of the WHO-China Joint Mission on Coronavirus Disease 2019 (COVID-19). URL available at: https://www.who.int/docs/ defaultsource/coronaviruse/who-china-joint-mission-on-covid-19final-report.pdf

4. Li X, Xu S, Yu M, Wang K, Tao Y, Zhou Y, Shi J, Zhou M, Wu B, Yang Z (2020) Risk factors for severity and mortality in adult COVID-19 inpatients in Wuhan. J Allergy Clin Immunol 146(1):110-118

5. Henry BM, de Oliveira MHS, Benoit S, Plebani M, Lippi G (2020) Hematologic, biochemical and immune biomarker abnormalities associated with severe illness and mortality in coronavirus disease 2019 (COVID-19): a meta-analysis. Clin Chem Lab Med (CCLM) 58(7):1021-1028

6. Onder G, Rezza G, Brusaferro S (2020) Case-fatality rate and characteristics of patients dying in relation to COVID-19 in Italy. JAMA 323(18):1775-1776
7. Rezaei R, Aslani S, Marashi M, Rezaei F, Sharif-Paghaleh E (2018) Immunomodulatory effects of vitamin D in influenza infection. Curr Immunol Rev 14(1):40-49

8. Dancer RC, Parekh D, Lax S, D'Souza V, Zheng S, Bassford CR, Park D, Bartis D, Mahida R, Turner AM (2015) Vitamin D deficiency contributes directly to the acute respiratory distress syndrome (ARDS). Thorax 70(7):617-624

9. Parekh D, Thickett RD, Turner AM (2013) Vitamin D deficiency and acute lung injury. Inflamm Allergy-Drug Targets (Formerly Current Drug Targets-Inflammation \& Allergy) 12(4):253-261

10. Grant WB, Lahore H, McDonnell SL, Baggerly CA, French CB, Aliano JL, Bhattoa HP (2020) Evidence that vitamin D supplementation could reduce risk of influenza and COVID-19 infections and deaths. Nutrients 12(4):988

11. Jakovac H (2020) COVID-19 and vitamin D-is there a link and an opportunity for intervention? Am J Physiol-Endocrinol Metab 318(5):E589-E589

12. Kearns MD, Alvarez JA, Seidel N, Tangpricha V (2015) Impact of vitamin D on infectious disease. Am J Med Sci 349(3):245-262

13. Ali N (2020) Role of vitamin D in preventing of COVID19 infection, progression and severity. J Infect Public Health 13(10):1373-1380

14. Teymoori-Rad M, Shokri F, Salimi V, Marashi SM (2019) The interplay between vitamin D and viral infections. Rev Med Virol 29(2):e2032

15. Fang Y, Zhang H, Xie J, Lin M, Ying L, Pang P, Ji W (2020) Sensitivity of chest CT for COVID-19: comparison to RT-PCR. Radiology 296(2):115-117

16. Li K, Fang Y, Li W, Pan C, Qin P, Zhong Y, Liu X, Huang M, Liao Y, Li S (2020) CT image visual quantitative evaluation and clinical classification of coronavirus disease (COVID-19). Eur Radiol 30:4407-4416

17. Zhou F, Yu T, Du R, Fan G, Liu Y, Liu Z, Xiang J, Wang Y, Song $\mathrm{B}, \mathrm{Gu} \mathrm{X}$ (2020) Clinical course and risk factors for mortality of adult inpatients with COVID-19 in Wuhan, China: a retrospective cohort study. Lancet 395:1054-1056

18. Martineau AR, Jolliffe DA, Hooper RL, Greenberg L, Aloia JF, Bergman P, Dubnov-Raz G, Esposito S, Ganmaa D, Ginde AA (2017) Vitamin D supplementation to prevent acute respiratory tract infections: systematic review and meta-analysis of individual participant data. BMJ 356:i6583

19. Ilie P, Stefanescu S, Smith L (2020) The role of Vitamin D in the prevention of Coronavirus Disease 2019 infection and mortality. Aging Clin Exp Res 1-4 (Epub ahead of print)

20. Scharla S (1998) Prevalence of subclinical vitamin D deficiency in different European countries. Osteoporos Int 8:S7

21. Ebadi M, Montano-Loza AJ (2020) Perspective: improving vitamin D status in the management of COVID-19. Eur J Clin Nutr 74(6):856-859

22. Abrishami A, Samavat S, Behnam B, Arab-Ahmadi M, Nafar M, Sanei Taheri M (2020) Clinical course, imaging features, and outcomes of COVID-19 in kidney transplant recipients. Eur Urol 78(2):281-286. https://doi.org/10.1016/j.eururo.2020.04.064

23. Sosa Henríquez M, de Tejada G, Romero MJ (2020) Cholecalciferol or calcifediol in the management of vitamin D deficiency. Nutrients. https://doi.org/10.3390/nu12061617

24. Quesada-Gomez J, Bouillon R (2018) Is calcifediol better than cholecalciferol for vitamin D supplementation? Osteoporos Int 29(8):1697-1711

25. Zhao W, Zhong Z, Xie X, Yu Q, Liu J (2020) Relation between chest CT findings and clinical conditions of coronavirus disease (COVID-19) pneumonia: a multicenter study. Am J Roentgenol 214(5):1072-1077 